\title{
URBANIDADE, PRODUÇÃO AGRÍCOLA E CONSERVAÇÃO AMBIENTAL - ESTUDO DE CASO NA REGIÃO DO VALE DO TAQUARI/RS/BRASIL
}

\author{
C. REMPEL, R. R. ECKHARDT, E. MARKUS, C. C. S. CYRNE e E. PÉRICO \\ Centro Universitário UNIVATES \\ crempel@univates.br
}

Artigo submetido em setembro/2014 e aceito em fevereiro/2015

DOI: $10.15628 /$ holos.2015.2365

\section{RESUMO}

O processo de urbanidade e a prática agrícola convencional ocorrem constantemente, modificando as condições do ambiente natural e transformando áreas vegetadas contínuas em fragmentos florestais. O objetivo deste estudo foi verificar a existência de relação entre a densidade populacional, o uso e cobertura da terra e os hotspots e firepoints existentes na região do Vale do Taquari - RS. Para tanto, foram gerados mapas de densidade populacional e de zoneamento ecológicoeconômico com áreas indicadas para conservação. Por meio da análise dos resultados, discutiu-se a melhor forma de conservar e ao mesmo tempo produzir. Além das alternativas trazidas pela agroecologia, sugere-se que as áreas aptas para a produção sejam melhor exploradas, enquanto que as regiões com restrições mantenham áreas mais extensas e conservadas. Fragmentos diminutos, apesar de servirem como ilhas conectivas, não cumprem a mesma função ambiental que fragmentos extensos, principalmente devido à influência de borda que sofrem.

PALAVRAS-CHAVE: Zoneamento ecológico-econômico, Fragmentação, Agroecologia, hotspots, firepoints.

\section{URBANITY, AGRICULTURAL AND ENVIRONMENTAL CONSERVATION: CASE STUDY IN THE REGION VALE DO TAQUARI/RS/BRASIL}

\begin{abstract}
The process of urbanity and standard agricultural practice occur constantly, changing the natural environmental conditions and transforming continuous vegetated areas into forest fragments. The aim of this study was to verify the existence of a connection among population density, land cover and land use, and the existing hotspots and firepoints in Vale do Taquari/RS/Brazil. Therefore, maps of population density and of ecological-economical zoning areas suitable for conservation were generated. By analyzing
\end{abstract}

the results, we discuss the best way of preserving and at the same time of producing. In addition to the alternatives introduced by agroecology, it is suggested that the suitable areas for production have to be well explored, while the regions with restrictions maintain more extensive and preserved areas. Tiny fragments, despite of serving as connective islands, do not carry out the same environmental function as the extensive fragments, mainly due to the influence of edge effect.

KEYWORDS: Ecological-economic zoning, Fragmentation, Agroecology, hotspots, firepoints. 


\section{INTRODUÇÃO}

Desde que o homem deixou de ser um caçador/coletor e começou cultivar alimentos, os impactos do uso da terra passaram a ser inevitáveis. É inegável a relação do ser humano com o ambiente natural que habita ao longo da história da humanidade. Desde os primórdios, a ideia era desbravar, desmatar, domesticar, estruturar o convívio social, enfim transformar e adaptar os ambientes às suas necessidades. No entanto, é preciso uma compreensão integrada do homem com o ambiente para que os impactos, inevitáveis, sejam os menores possíveis, indo assim, ao encontro do tão discutido desenvolvimento sustentável.

O presente artigo não apresenta oposição ao plantio, nem tampouco condena práticas agrícolas, no entanto, apresenta aspectos do impacto do uso não planejado da terra (a urbanidade e a produção agrícola), sobre o ambiente; impacto este que reduz as áreas naturais de fundamental importância ambiental para a garantia do equilíbrio e da qualidade da vida.

Conservar áreas naturais é importante para manter-se a biodiversidade e também está relacionado ao fato de que os fragmentos florestais mantêm a umidade do solo, fixam a terra e nutrientes para que esta não seja assoreada pelas águas. Assim, o solo mantém suas propriedades essenciais para a produção de culturas e o ambiente mantém-se em equilíbrio o que evita o aparecimento e/ou aumento de diversas pragas. Conservar, portanto, é fundamental para garantir condições mínimas de sustentabilidade.

Glantz (2007) apresenta uma pirâmide de ações antrópicas sobre o ambiente natural (algumas benéficas), onde há tênue distância entre os hotspots (fragmentos a serem conservados) e os firepoints (áreas onde não há mais o que conservar), apontando que políticas de recuperação ambiental são necessárias para a manutenção e o equilíbrio natural das regiões (Figura 1).

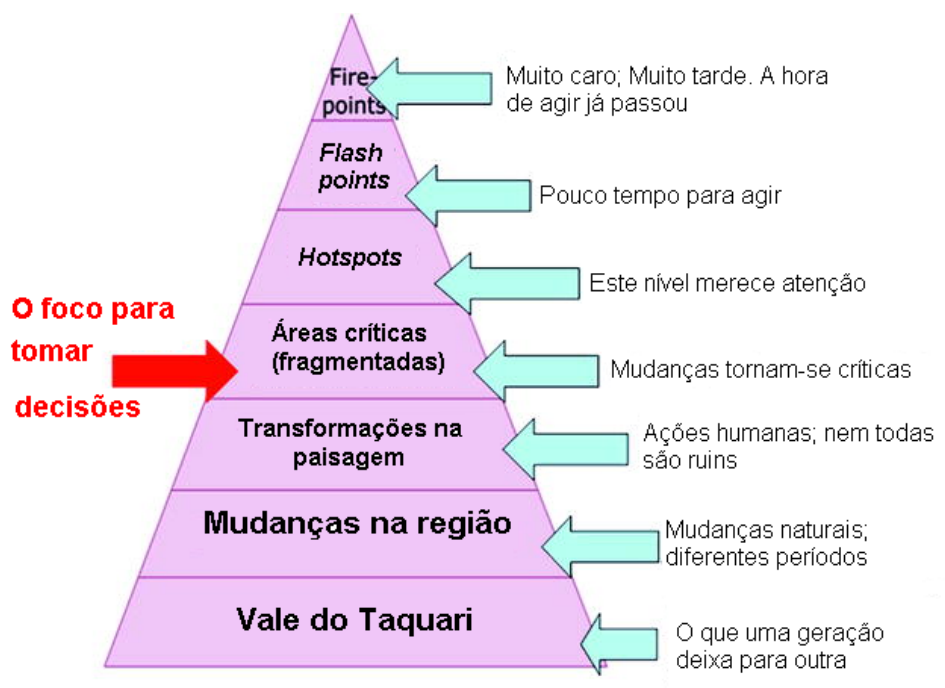

Figura 1 - Pirâmide de hotspots (áreas de conservação) para o Vale do Taquari FONTE: Rempel, 2009, adaptado de Glantz, 2007

Para a região do Vale do Taquari, RS, Brasil (REMPEL, 2009) é apresentada uma proposta de zoneamento ambiental com áreas indicadas para conservação. Uma análise mais aprofundada dos dados gerados permite a avaliação do efeito da urbanidade (WRBKA et al., 2004) sobre o 
ambiente onde percebe-se que os municípios com maior população são os que justamente apresentam maior fragmentação da matriz florestal bem como menores áreas destes fragmentos e maior distância entre estes.

O tamanho médio e a densidade de fragmentos são parâmetros que estão diretamente relacionados à qualidade de habitat, pois quanto maior o tamanho dos fragmentos e quanto mais próximos uns dos outros, maior a possibilidade de intercâmbio genético entre eles e, portanto, maior a persistência e estabilidade dos processos ecológicos atuantes na paisagem.

A legislação ambiental brasileira, por meio do Código Florestal, Lei 12.651/2012 (BRASIL, 2012) impõe condições de restrição do uso da terra como as Áreas de Preservação Permanente (APP) (margens de cursos d'água, topo de morro e declividades superiores a 45으), além das áreas de Reserva Legal (variando conforme o bioma).

Essa legislação gera inúmeros impasses entre o poder público, judiciário, produtores, cientistas ambientais, ONGs e ambientalistas. No entanto, nessas discussões muito pouco se debate sobre o porquê destas restrições de uso da terra e que alternativas se apresentam, principalmente aos pequenos produtores.

O presente artigo tem por objetivo apresentar aspectos da utilização da terra do Vale do Taquari, indicar as áreas para conservação, através de critérios ambientais como tamanho e forma dos fragmentos, distância entre eles, área interna e outros, demonstrando os hotspots e firepoints do Vale do Taquari, além de expor as áreas com aptidão agrícola, que não se sobrepõe às áreas indicadas para conservação.

\section{MATERIAL E MÉTODOS}

\section{1 Área de estudo}

A área de estudo compreende a região geopolítica conhecida como Vale do Taquari (Figura 2), localizada na região Centro-Leste do estado do Rio Grande do Sul, composta por 37 municípios*, numa área de $4.869,05 \mathrm{~km}^{2}$, com 331.588 habitantes (IBGE 2010), cuja densidade populacional é de $68,1 \mathrm{hab} / \mathrm{km}^{2}$.

A maioria dos municípios do Vale do Taquari tem sua economia baseada na atividade primária, principalmente na atividade agropecuária de cunho familiar. São exceção os municípios localizados às margens do rio Taquari, com destaque para Lajeado, Estrela, Taquari, Teutônia, Arroio do Meio e Encantado que apresentam considerável desenvolvimento industrial e comercial.

A região do Vale do Taquari apresenta características fisionômicas muito particulares: uma parte dela está localizada na encosta inferior do Planalto Meridional, outra na Depressão Central Gaúcha e outra na região conhecida como Campos de Cima da Serra. A área localizada na encosta inferior do Planalto Meridional é caracterizada pelo escarpamento acentuado devido à dissecação provocada pelo curso inferior do Rio Taquari, formando assim pontos de grande aclive e porções com os típicos morros testemunhos. Originalmente desenvolvia-se nesta área a Floresta Estacional Decidual e Semidecidual, cuja superfície mapeada é de aproximadamente $31.000 \mathrm{~km}^{2}$, ocupando assim a maior parte da vertente sul do Planalto das Araucárias e as áreas dos terraços aluviais do rio Jacuí e seus respectivos afluentes. Os solos que se formam nestas 
encostas são muito utilizados para a silvicultura e fruticultura, principalmente devido às limitações quanto à declividade (IBGE, 1986).

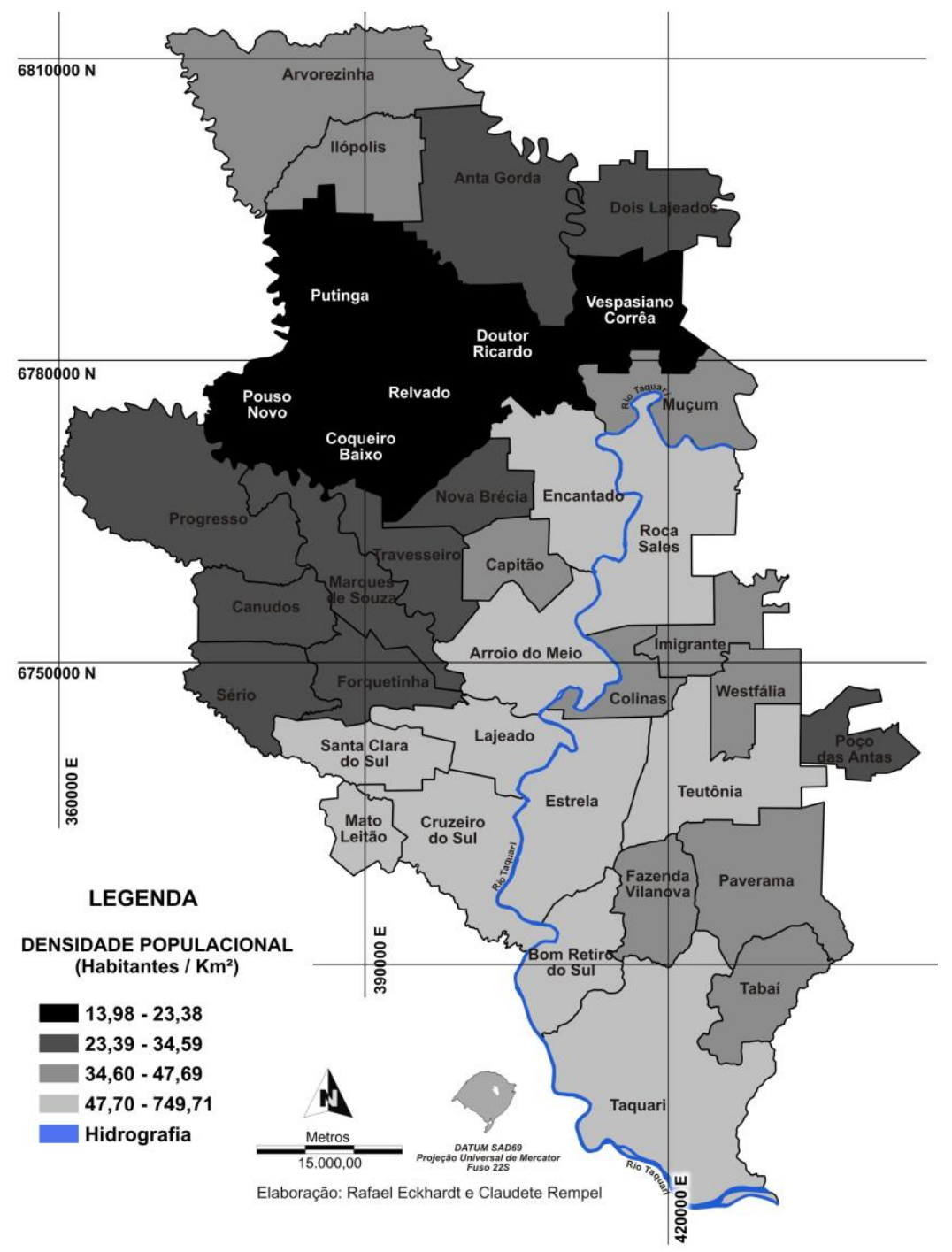

Figura 2 - Densidade populacional dos municípios do Vale do Taquari

* o município de Mato Leitão deixou de fazer parte da Região do Vale do Taquari após a realização do estudo

Uma pequena porção do Vale do Taquari localiza-se na região da Depressão Central Gaúcha, onde se formam terraços aluviais que também estavam cobertos pela Floresta Estacionais Decidual, hoje muito modificados por ação antrópica e utilizados para plantio de culturas anuais(IBGE, 1986).

\subsection{Material}

Imagens de satélite:

- Bandas 3, 4 e 5 do Satélite Landsat7, órbita/ponto 222/080 ,de 04/02/2002.

- Bandas 3, 4 e 5 do Satélite Landsat7, órbita/ponto 221/080, de 31/01/2003.

- Bandas 3, 4 e 5 do Satélite Landsat7, órbita/ponto 221/081 ,de 31/01/2003.

Cartas Topográficas da Diretoria do Serviço Geográfico do Exército em escala 1:50.000.

Global Positioning System (GPS) - Sistema de Posicionamento Global.

Software Idrisi Kilimanjaro. 


\subsection{Métodos}

A organização de informações sobre urbanidade, produção agrícola e conservação ambiental da região do Vale do Taquari partiu de uma base cartográfica digital de informações, envolvendo o uso de cartas topográficas analógicas de toda a área de estudo, na escala 1:50.000, e imagens de satélite. Essas cartas foram convertidas para o formato digital por scanner de mesa, georreferenciadas no Sistema de Informação Geográfica (SIG) Idrisi Kilimanjaro e vetorizadas as curvas de nível, a malha rodoviária e a rede hidrográfica.

Essa base cartográfica permitiu classificar o uso e cobertura do solo do Vale do Taquari, em: Floresta Estacional Decidual, Floresta Ombrófila Mista, Floresta Industrial, Vegetação Secundária, Campos (nativos e antrópicos), Agricultura, Solo Exposto, Água, Áreas Urbanas e Banhados (Figura 5).Os usos existentes na área de estudo, além de permitirem a quantificação das áreas florestais naturais, de uso urbano e de uso agropecuário, foram cruzados com o mapa de zoneamento ambiental com álgebra de mapas, permitindo a obtenção da condição de adequabilidade do uso do solo em função da zona ambiental. Essa informação permite mensurar de forma mais direta se os usos atuais são suportados em função da característica do terreno.

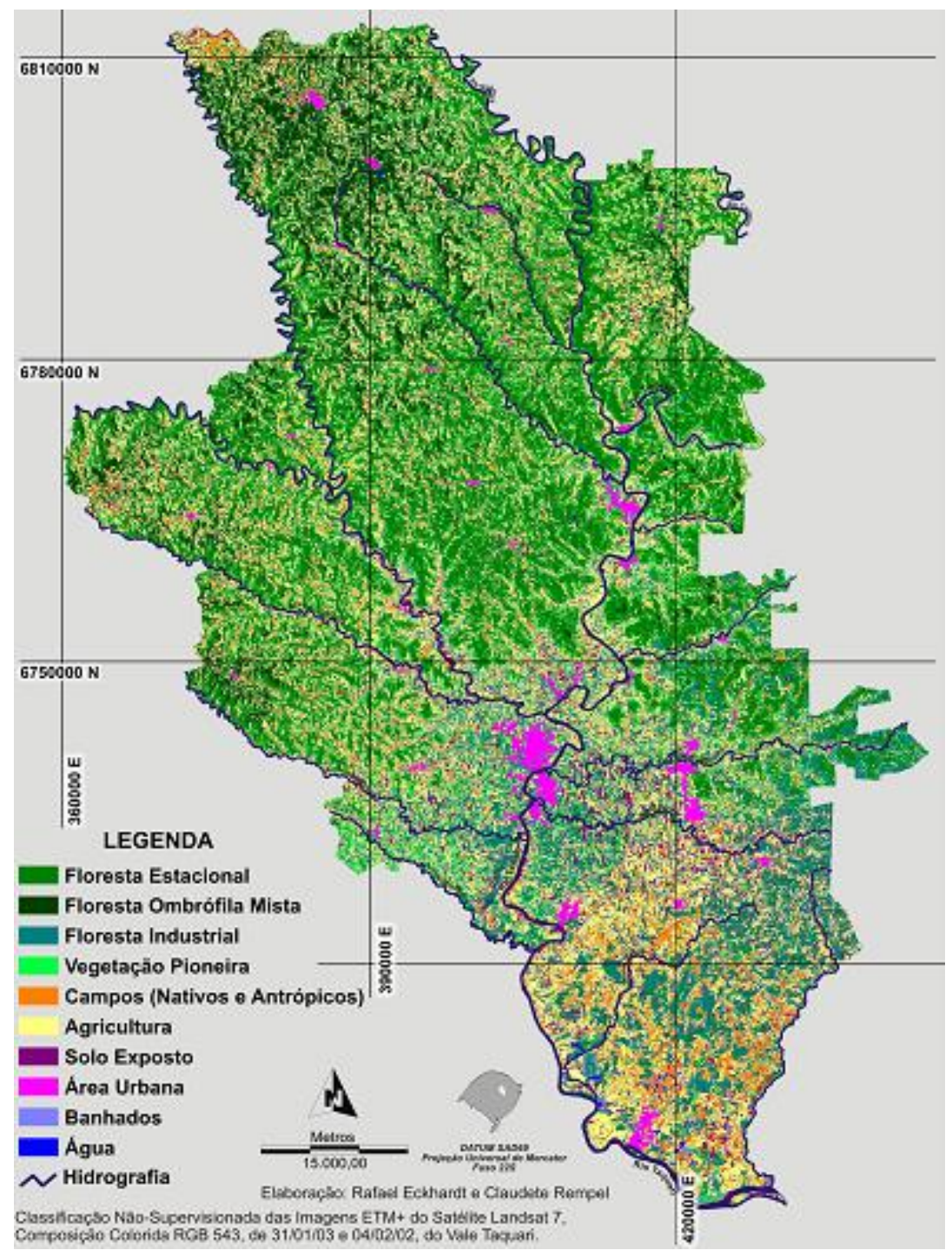

Figura 3 - Mapa de uso e cobertura do solo do Vale do Taquari FONTE: Eckhardt et al. (2007) 
Paralelamente, elaborou-se o mapa da condição de risco do uso da terra, de acordo com a proposta metodológica de Rempel (2009). Neste mapa (Figura 4) foram delineadas as áreas em conflito com a legislação (áreas de APP com uso antrópico), área de risco (região com utilização inadequada para a zona em que se encontra), área sem risco (região da zona de uso intensivo cuja utilização está adequada à legislação) e área com aptidão agrícola, que foi considerado o solo e cobertura da terra das regiões que não estão em "conflito" com a legislação em áreas de declividade superior a $20 \%\left(\sim 35^{\circ}\right)$. Assim as áreas "com aptidão agrícola" são as que suportariam, em longo prazo, os usos que atualmente lhe são imputados.

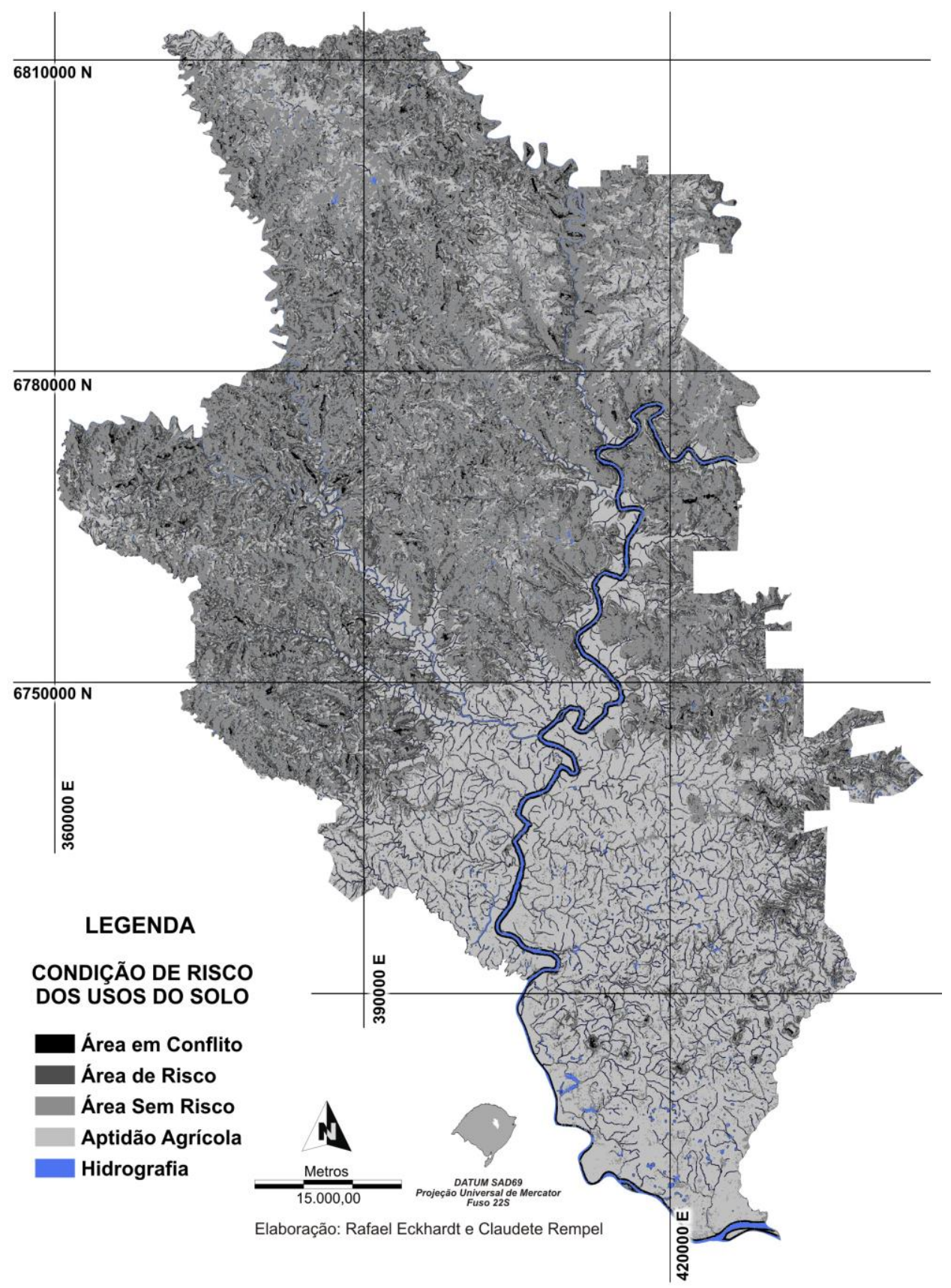

Figura 4 - Mapa da condição de risco do uso da terra do Vale do Taquari FONTE: Rempel (2009) 


\section{RESULTADOS E DISCUSSÃO}

As imagens de satélite georreferenciadas e "mosaicadas" permitiram de limitar as Áreas de Preservação Permanentes (APP's) da área de estudo, segundo os critérios constantes no Novo Código Florestal Brasileiro (BRASIL, 2012) e de acordo com as orientações contidas nas resoluções 302 e 303 do Conselho Nacional do Meio Ambiente (CONAMA), de 20 de março de 2002 (BRASIL, 2002). A identificação e delimitação das áreas enquadradas como APP's resultam em zona de conservação ambiental obrigatória e na qual os usos antrópicos não são permitidos.

Além da zona ambiental de APP, restritiva e estabelecida por legislação federal específica, foram indicadas as zonas de uso restrito e zona de uso intensivo, conforme proposto por Ramalho Filho e Beek (1995). Estas zonas indicam que as principais restrições para a produção agropecuária, sob a ótica econômica e ambiental, estão relacionadas com a declividade do terreno. Sob a ótica econômica, quanto maiora declividade do terreno menor será a possibilidade de mecanização da produção e maiores serão os custos para evitar os impactos ambientais decorrentes da produção, como por exemplo, a erosão e a perda de solo e de nutrientes. Sob a ótica ambiental, quanto maior a declividade do terreno, maior o risco de danos ambientais em decorrência do uso antrópico dessas áreas. Em caso de ausência de manejo da atividade agropecuária, impactos sobre o solo e sobre a drenagem estão associadas com elevadas declividades.

Com base na discussão acima, no presente estudo, definiu-se uma zona de uso intensivo e de uso restrito com base na declividade do terreno. A Zona de Uso Intensivo, de acordo com as orientações de Ramalho Filho e Beek (1995), suporta toda a gama de usos antrópicos possíveis e está compreendida em terrenos com declividades de 0 a $20 \%\left(\sim 35^{\circ}\right)$, classificados como terrenos planos a ondulados, respectivamente. A Zona de Uso Restrito, enquadrada em terrenos com declividades de $20 \%\left(\sim 35^{\circ}\right)$ a $100 \%\left(45^{\circ}\right)$ - terrenos com declividade forte ondulada a escarpada -, apresenta relativa fragilidade ambiental. Essa zona ambiental é bastante seletiva quanto aos usos à que pode ser submetida, porém isto não implica na inviabilização do uso deste território. Em termos práticos, o uso destas áreas requer uma série de restrições, condicionantes de manejo, bem como o emprego de modelos ou tecnologias de exploração adequadas. A delimitação dessas duas zonas, somadas com a APP, resultou no zoneamento ambiental do Vale do Taquari (Figura 5).

Após, gerados os mapas de densidade populacional e o de zoneamento ecológicoeconômico com áreas indicadas para conservação foi realizada a comparação entre os mesmos com o objetivo de verificar se há relação entre a densidade populacional, o uso da cobertura da terra e os hotspots e firepoints existentes na região do Vale do Taquari.

Observando os mapas da condição de risco do uso da terra do Vale do Taquari e o de zoneamento ambiental do Vale do Taquari com o de densidade populacional percebe-se que as regiões com maior densidade populacional também são aquelas com maior aptidão agrícola, e também com os firepoints, ou seja, regiões onde a retirada desordenada dos recursos naturais fez com que os fragmentos florestais remanescentes não sejam mais passíveis de conservação.

Da mesma forma, regiões com menor densidade populacional também são aquelas que correspondem a maior parte das áreas de proteção permanente e zonas de uso restrito, bem como apresentam as áreas indicadas para conservação (hotspots). 
No processo de urbanização há um crescimento demográfico associado ao adensamento populacional em pequenas e médias cidades e também em metrópoles. O movimento acelerado de urbanização deu-se, como afirmam Bargos e Matias (2012), na maioria das vezes, de uma forma não planejada desconsiderando a necessidade do estabelecimento de políticas públicas de planejamento e gestão que buscassem a qualidade ambiental. Porém, é necessário considerar que o homem integra-se e interage com a natureza transformando-a e adaptando-a a sua necessidade (FARINA, 2006).

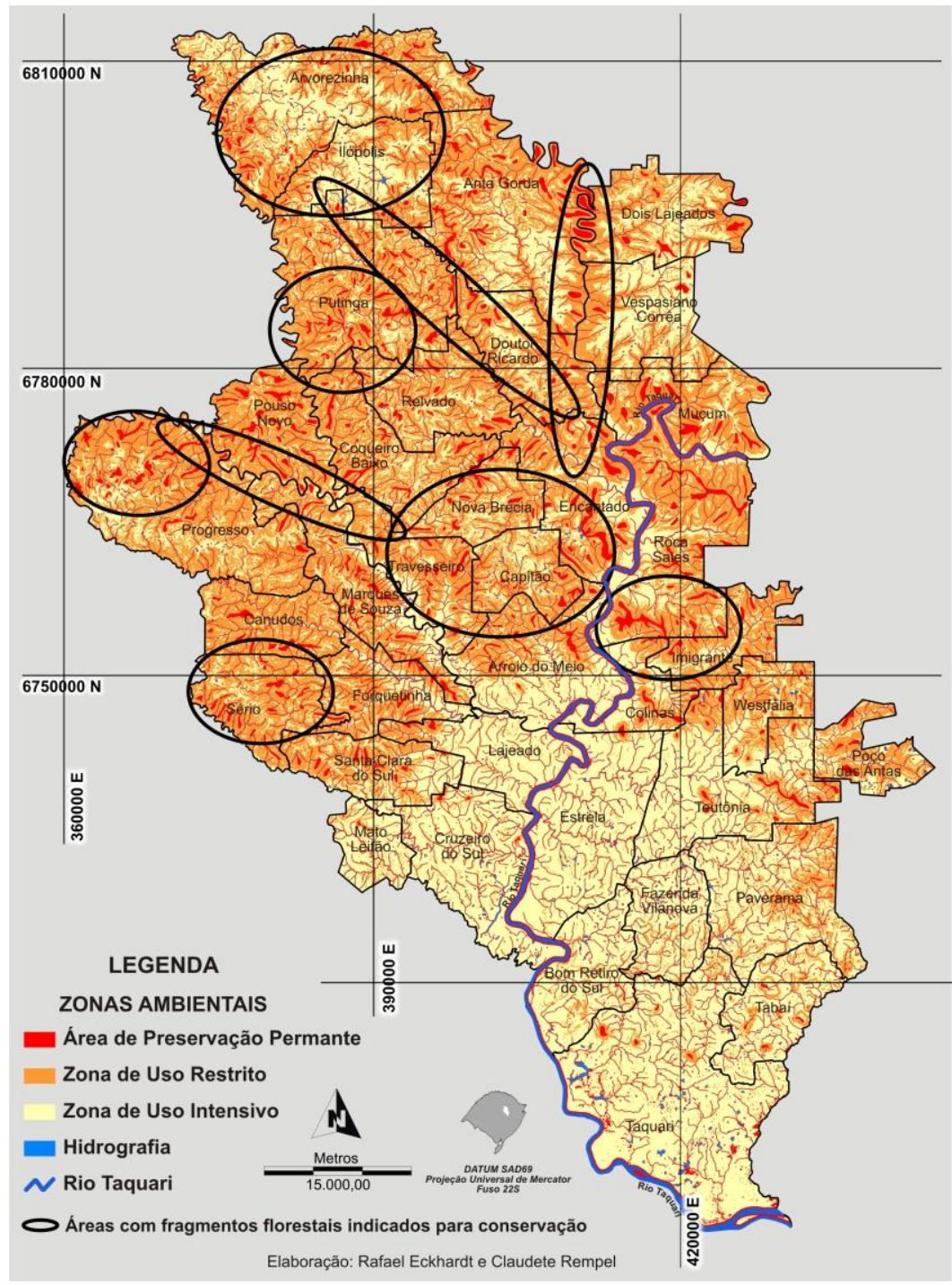

Figura 5- Zoneamento Ambiental do Vale do Taquari, sobrepondo informações do previsto na legislação com o obtido na análise por métricas da paisagem (elipses)

FONTE: Rempel (2009)

Nesta direção, é importante desenvolver uma visão mais ampla da cidade, pois conforme Carvalho (2001) a cidade pode ser vista como um espaço de conflito em que sociedade e natureza se encontram em desequilíbrio. Para atingir o equilíbrio, é necessário que o poder público estabeleça políticas norteadoras da ação dos homens. A própria constituição brasileira aponta, segundo Silva e Werle (2007), em diferentes artigos, especialmente o Art. 225, que todos têm direito a um meio ambiente ecologicamente equilibrado, colocando sob a responsabilidade do poder público, a viabilização deste equilíbrio. 
Conforme Silva e Werle (2007), mesmo que constitucionalmente previsto, poucos municípios utilizam instrumentos de gestão urbana e ambiental, sendo também baixo o número daqueles que contam com um plano diretor que aborde as diferentes dimensões possíveis a um desenvolvimento sustentável. Seria importante a revalorização do planejamento estratégico com o intuito de pensar a cidade como um todo orgânico, composto de diferentes partes interligadas formando algo complexo. O planejamento deveria pautar-se pela recuperação e manutenção do equilíbrio.

Segundo Ojima (2007) em um primeiro momento a ocupação dos espaços tem por base a questão econômica e social em detrimento das questões ambientais. No entanto, é possível afirmar que esta opção resulta no acúmulo de problemas socioambientais, pois os centros urbanos tornam-se espaços de miséria, desemprego e conflitos ambientais. Farina (2006) afirma ainda que o modelo de planejamento, quando adotado, é parcial e fragmentado, preocupandose somente com a definição da ocupação da terra, do solo e da infraestrutura, sem considerar as questões mais complexas, deixando de abarcar os aspectos ambientais. Entretanto, mais recentemente já ocorrem mudanças nas questões de planejamento devido ao surgimento de diferentes movimentos ecológicos. Assim, pode-se verificar que o processo de planejamento passa a ter como fim não somente os aspectos econômicos, mas também a viabilização de uma melhor qualidade de vida, resgatando a unidade, o equilíbrio, entre homem e natureza.

Certo é que as decorrências negativas do processo de urbanização são cada vez mais reconhecidas, acompanhadas, monitoradas e sendo necessária a intervenção, se não para a reversão da situação, para a minimização do desequilíbrio vigente.

A observação das interações entre a estrutura da paisagem (tamanho, forma, arranjo e conexão entre os elementos) e seus processos ecológicos permite que vários fenômenos sejam averiguados. Entre estes podemos citar: a capacidade do meio em recuperar-se e, apesar da mudança, continuar em equilíbrio; o tempo de sobrevivência de um sistema ou de algum de seus componentes; as consequências das mudanças dos movimentos e transporte de agentes (organismos, água e ar) entre os elementos da paisagem; a medida da facilidade de ocorrência dos fluxos biológicos (conectividade); a evolução da fragmentação relacionada aos tipos de perturbação; os efeitos de borda dos fragmentos; os pontos de ligação (áreas de habitat dispersas), que facilitam o fluxo entre manchas, e a variação da diversidade da paisagem (PÉRICO; CEMIN, 2006). Estes requisitos são comumente desconsiderados pelos planejadores brasileiros, apesar de permitirem a redução dos efeitos dos impactos cumulativos no meio (SANTOS, 2004; FROTA, 2006; PEIXOTO, 2008; GUIMARÃES et al., 2012).

Como consequência da fragmentação pode-se considerar a perda da biodiversidade microbiológica do solo, da diversidade genética e a redução da densidade ou abundância na alteração da estrutura da vegetação (BORGES et al., 2004). Devido à fragmentação o processo de extinção de populações locais ou espécies ocorre de forma mais veloz, limitando o potencial de dispersão e colonização, bem como reduzindo o tamanho efetivo das populações e facilitando o endocruzamento (PRIMACK; RODRIGUES, 2001).

Ao largo das discussões sobre a resolução de problemas ambientais estão os problemas sociais. Não se pode dissociar estas discussões, não é possível imaginar que o homem deixará de gerar impacto sobre a vegetação nativa original, sendo que vivemos atualmente em um ambiente artificial. Portanto, é necessária a revisão das formas de produção, onde a busca pelo 
desenvolvimento deverá ocorrer com menor impacto aos recursos naturais, havendo uma interação de forma mais harmônica e equilibrada.

Através de agriculturas denominadas de "alternativas" ou "ecológicas" não se limitam ao questionamento dos aspectos técnicos e econômicos no meio rural, mas também incorporam, em suas discussões e práticas, as dimensões sociais e políticas que interferem na sustentabilidade dos sistemas produtivos.

A agroecologia (ALTIERI, 1989; AQUINO; ASSIS, 2007) é considerada uma ciência que contribui para o entendimento dos possíveis modos de otimização dos agroecossistemas, considerando seus ciclos minerais, fluxos energéticos, processos biológicos e relações socioeconômicas, contribuindo, dessa forma, para a promoção de estratégias voltadas para o desenvolvimento rural sustentável. Objetiva analisar as relações entre as pessoas, culturas, solos e animais. Portanto, recebe contribuições de diversas áreas do conhecimento com o intuito de apoiar os processos de transição da agricultura convencional e é um instrumento importante na implementação de estratégias para viabilizar produções agrícolas em pequena escala sob administração familiar.

Tendo em vista que as condições essenciais para a sustentabilidade seja a busca pela compatibilização entre o crescimento econômico e a qualidade ambiental, torna-se fundamental que as limitações impostas pelo ambiente sejam consideradas pelos administradores, no momento da implementação e execução das políticas de desenvolvimento econômico.

A questão ambiental também deve ser um importante aspecto condicionante para determinar a dispersão ou concentração da população urbana, sendo preciso questionar qual das duas opções é a mais adequada, tomando por base as características da vegetação existente. Seria mais interessante buscar preservar as diminutas áreas verdes que se dispõe ou concentrar a área de recuperação em outro espaço? Cada situação levará a uma resposta diferente, porém qualquer que seja, trará suas consequências. Cada situação influenciará no momento de se realizar o cadastro ambiental rural (CAR) e o proprietário que estiver com a área de preservação permanente irregular poderá não obter financiamento ou crédito do governo.

\section{CONCLUSÕES}

Através da análise do cruzamento das informações dos mapas de uso e cobertura da terra da região do Vale do Taquari com o mapa de densidade populacional pode-se concluir que as regiões com maior densidade populacional possuem também os menores fragmentos florestais. Analisando o mapa com as áreas indicadas para conservação percebe-se novamente que estas áreas localizam-se nas regiões com menores densidades populacionais, demonstrando os hotspots para esta região são estas áreas indicadas para conservação e que os firepoints do Vale do Taquari são as áreas com maior densidade populacional que, geograficamente, localizam-se na porção sul da região. Na região sul, o custo para recuperação e conservação dos fragmentos remanescentes será muito elevado, portanto, nessas áreas com aptidão agrícola, segundo mapa das condições de risco e uso da região, são indicadas para práticas de cultivo sustentáveis. 


\section{REFERÊNCIAS}

1. AltiERI, M. A. Agroecologia: As Bases Científicas da Agricultura Alternativa. Rio de Janeiro: PTA/FASE, 1989.

2. AQUINO, A. M. DE, ASSIS, R. L. de. Agricultura orgânica em áreas urbanas e periurbanas com base na agroecologia. Ambiente \& sociedade, v. 10, n. 1, p. 137-150. 2007.

3. BARGOS, D. C., MATIAS, L. F. Mapeamento e análise de áreas verdes urbanas em Paulínia (SP): estudo com a aplicação de geotecnologias. Sociedade \& Natureza, v. 24, n. 1, p. 143156, 2012.

4. BORGES, L. F. R. et al. Inventário de fragmentos florestais nativos e propostas para seu manejo e o da paisagem. Cerne, v. 10, n. 1, p. 22-38. 2004.

5. BRASIL. Lei Federal no. 12.651, de 25 de maio de 2012. Institui o Novo Código Florestal Brasileiro. Diário Oficial [da] República Federativa do Brasil, Brasil, DF, 25 mai. 2012. Disponível em $\quad$ http://www.planalto.gov.br/ccivil_03/_Ato20112014/2012/Lei/L12651.htm> Acesso em: 10 jul. 2014

6. BRASIL. Resolução CONAMA 302, de 20 de março de 2002. Definições de Áreas de Preservação Permanente em Reservatórios Artificiais. D.O.U. 13.05.2002

7. BRASIL. Resolução CONAMA 303, de 20 de março de 2002. Dispõe sobre parâmetros, definições e limites de Áreas de Preservação Permanentes. D.O.U. 13.05.2002

8. ECKHARDT, R.R. et al. Proposta de zoneamento ambiental para a região político-econômica do Vale do Taquari (RS). CLIMEP - Climatologia e Estudos da Paisagem, v. 3, n. 2, p. 5-38, 2008.

9. FARINA, F. Abordagem sobre as técnicas de geoprocessamento aplicadas ao planejamento e gestão urbana. Cadernos EBAPE.BR, v.4, n.4, dez. 2006.

10. FROTA, P. V. Propostas para gestão integrada de recursos hídricos na Bacia Hidrográfica do Rio Jardim - DF. 2006. 167p. Dissertação (Mestrado) - Universidade de Brasília, Brasília.

11. GLANTZ, M. H. Aral SeaBasin: a sea dies, a seaalsoRises. Ambio, v. 36, n. 4, jun 2007. p. 323327

12. GUIMARÃES, S. T. L. et al. (orgs). Gestão de áreas de riscos e desastres ambientais. Rio Claro: IGCE/UNESP/RIO CLARO, 2012

13. IBGE - Instituto Brasileiro de Geografia e Estatística. Cidades@. 2010. Disponível em<http://www.cidades.ibge.gov.br/xtras/uf.php?lang=\&coduf=43\&search=rio-grande-dosul>. Acesso em: 15 de jul. 2014.

14. IBGE (Instituto Brasileiro de Geografia e Estatística). Ecologia, Geomorfologia, Pedologia, Vegetação, Uso potencial da Terra. Folha SH 22. Porto Alegre e parte das Folhas SH 21 Uruguaiana e SI 22. Rio de Janeiro, p. 541-632, 1986 (Levantamento de Recursos Naturais, 33)

15. OJIMA, R. Dimensões da urbanização dispersa e proposta metodológica para estudos comparativos: uma abordagem sócio espacial em aglomerações urbanas brasileiras. R. bras. Est. Pop., São Paulo, v. 24, n. 2, p. 277-300, jul./dez. 2007

16. PEIXOTO, J. A. S. Bahia de Todos os Santos: vulnerabilidades e ameaças. 2008. 192p. 
Dissertação (Mestrado) - Universidade Federal da Bahia, Salvador.

17. PÉRICO, E., CEMIN, G. Caracterização da paisagem do município de Arvorezinha, RS, com ênfase na dinâmica dos fragmentos florestais, por meio de sistemas de informações geográficas (SIGs). ScientiaForestalis, v. 70, n. 1, p.09-21, abr. 2006.

18. PRIMACK, R., RODRIGUES E. Biologia da conservação. Londrina. 328p. 2001.

19. RAMALHO F., A., BEEK, K.J. Sistema de avaliação da aptidão agrícola das terras. 3.ed. rev. Rio de Janeiro, EMBRAPA-CNPS, 1995. 65p.

20. REMPEL, C. A Ecologia de Paisagem e suas ferramentas podem aprimorar o Zoneamento Ambiental? O caso da região política do Vale do Taquari. 2009. 146p. Tese (Doutorado) Universidade Federal do Rio Grande do Sul, Porto Alegre.

21. SANTOS S, R. F. dos. Planejamento ambiental: teoria e prática. São Paulo: Oficina de Textos. 184 p. 2004.

22. SILVA, G. J. A. da; WERLE, H. J. S. Planejamento urbano e ambiental nas municipalidades: da cidade a sustentabilidade, da lei a realidade. PAISAGENS EM DEBATE: Revista Eletrônica da Área Paisagem e Ambiente, FAU/USP, n. 5, p. 24, dez. 2007.

23. WRBKA, T., et al. Linking pattern and process in cultural landscapes. An empirical study based on spatially explicit indicators. Land Use Policy. v. 21, p. 289-306, 2004. 